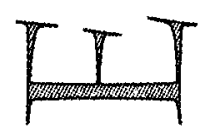

\title{
Academic Detailing to Influence Prescribing
}

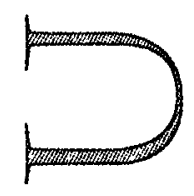

\begin{abstract}
A variety of sources influence prescribers in making informed, rational prescribing decisions. Traditionally, pharmacists have counted on their knowledge and drug therapy expertise to help sway decisions. But there are other tools, including using established sales techniques, that they can use to successfully influence prescribing.
\end{abstract}
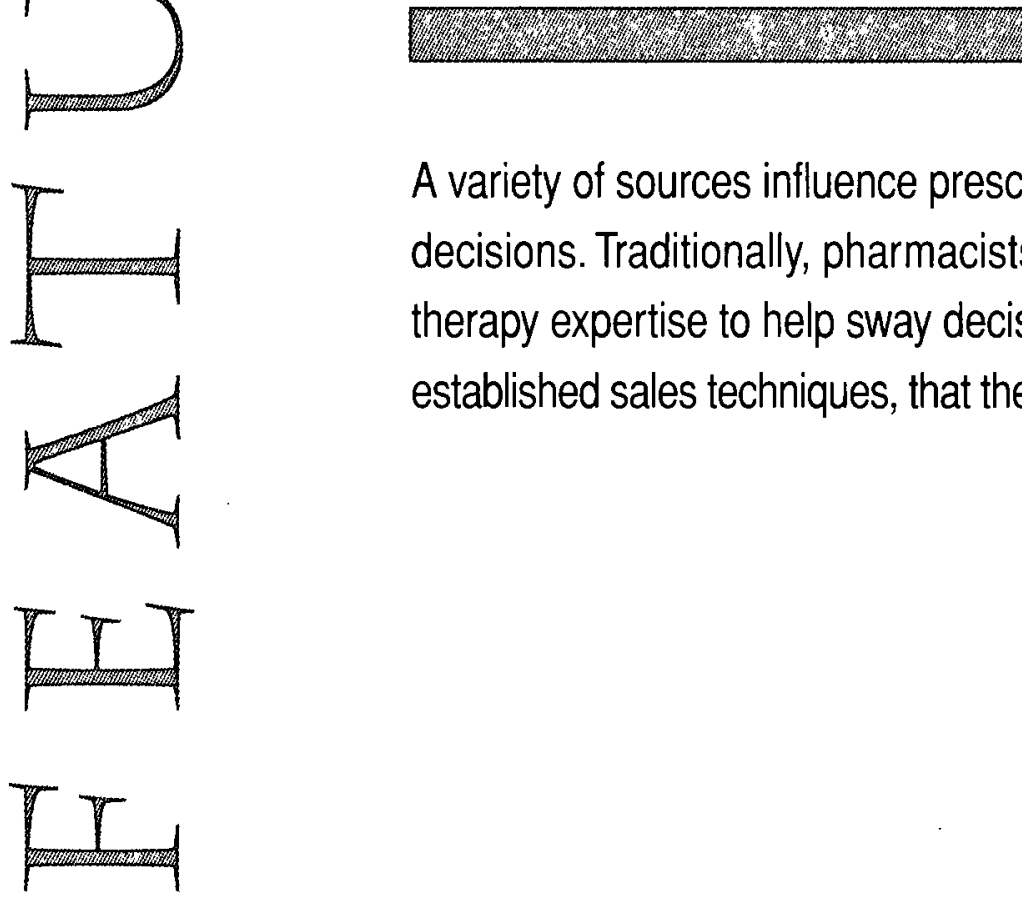

悬 he way a medication is approved, marketed, and used in the U.S. has changed significantly during the last decade. This change is due to a combination of factors. For example, advocacy groups and others, especially those associated with HIV/AIDS and Alzheimer's disease, have pressured the FDA to speed up the approval process for certain compounds. Elsewhere, direct-to-consumer (DTC) advertising has influenced consumers to request specific medications for various conditions.

Developments in managed care also have had an impact. Managed care organizations (MCOs) have grown in size and scope, and their armamentarium of medications has expanded to represent their larger, more diverse populations. At the same time, medication formularies, once the comerstone of health care cost control, have come under attack.

All of these changes have increased prescribing variability and decreased predictability. Consequently, pharmacists have lost some control over cost, product selection, and, ultimately, patient outcomes. Many MCOs are looking for
ALAN BARREUTHER, PHARM.D., FASHP, is Pharmacy Manager, HealthPartners Health Plans, Tucson, AZ.

Copyright (O 1997, Academy of Managed Care Pharmacy, Inc. All rights reserved

\section{A L A N B A R R U THER}


Table 1. Drug Use Evaluation/Drug Utilization Review Process

\begin{abstract}
Identify existing clinical guidelines for treatment of disease or use of drug. (Check national associations such as the American Psychiatric Association, government agencies like the Agency for Health Care Policy and Research, or consumer groups like the American Diabetic Association. Commercial sources are also available.)
\end{abstract}

Evaluate and revise existing guidelines or create facility-specific guidelines.

Gather data from chart review and/or medication records.

Tabulate data against existing thresholds and determine compliance rate.

Communicate results to medical staff using organization's established systems.

programs to help them regain a measure of control without sacrificing quality of life for patients.

\section{THAT WAS THEN}

Since the 1950 s, pharmacy practice has been on a path of steadily expanding clinical involvement. No longer are pharmacists simply dispensers of medication. Our concerns now encompass product selection, procurement, prescription, compliance, metabolism, response, and elimination. In addition, pharmacists are interested in using the lowest possible dose and climinating unnecessary medications from the patient's regimen.

Most pharmacists have been exposed to drug utilization review (DUR) or drug use evaluation (DUE) processes, used primarily and extensively by hospitals. Initially, these processes looked at specific medications to determine appropriateness of use. Costly medications often were targeted with hopes of reducing pharmacy expenses. In the managed care environment, this process has evolved to emphasize quality issues such as overuse, abuse, and noncompliance. Although cost clearly remains a factor, it is no longer the sole concern. Other quality of life indices, as well as potential for adverse event, are primary concerns (see Table 1).

Depending on the size of the facility and the number of charts involved, DUR/ DUE can be very time consuming. As computerization has become a standard of practice, DURIDUE has become less burdensome but still requires an investment of time.

Difficulties encountered with DUR DUE are legendary. Communication of findings is difficult, and findings often emphasize infractions and fail to recognize compliance. Many practitioners have difficulty understanding that measurement is not criticism. In some cases, practitioners object to the process used to identify their work as inappropriate, questioning the validity of results. In addition, the process was largely retrospective; and it is difficult to apply retrospective studies to create prospective change.

Outpatient application of the DUR/ DUE process has been tried by many MCOs. Until a standard medication claim form was created, attempts at DURDUE in the oulpatient environment were not entirely successful. Large numbers of clients, prescribers, prescriptions, and refills made the task of monitoring monumental, and MCOs that covered large geographic areas had logistics problems. Data collected from standard claims helped MCOs gather and report retrospective information, mainly for financial consideration.

Information compiled pursuant to standlardized claims was used by some investigators. For example, data collected by Medicare has been used to compile several reports. Examples include patterns of abuse and estimates of noncompliance in the elderly. However, organized educational programs were not directed at prescribers based on these results. over the years. Once again, this system started in the hospital environment and has since been implemented in numerous ambulatory programs. In its most liberal form, the open formulary allows a large selection of drugs and amounts to little more than a drug list. Closed formularies offer a limited selection of drugs in those
Formulary systems also have evolved categories designated essential and are usually prepared by representatives from many medical specialties who sit on the facility's Pharmacy and Therapeutics (P\&T) committee. In its more advanced form, the closed formulary may allow therapeutic substitution by the dispensing pharmacist; where state and local law allows, the pharmacist may automatically substitute a drug that is similar but not generically equivalent if endorsed by the P\&T committee. Recently, formulary systems have been criticized as being too restrictive. Critics also suggest that cost savings do not justify the severe restrictions.

\section{THIS IS NOW}

In recent years, there has been growing interest in documentation of drug interventions. This process dictates that the pharmacist document contact with physicians. Depending on the extent or evolution of the system, interventions may be reviewed for patterns or included in the patient record. Documentation of interventions is more likely to indicate that one-on-one consultation occurred and that a change, if any, followed. This method influences prescribing prospectively and is preventive in nature.

Various other quality assessment and improvement activities have been developed over the years to influence rational drug prescribing and monitoring. The current thrust is to encourage multidisciplinary, outcome-oriented techniques. Peer review, if blinded and completed in a spirit of improvement, can be very helpful. The Australian Society of Experimental and Clinical Pharmacologists and the Consumers' Health Forum of Australia articulated the basic theory of quality improvement in health care at their joint meeting in 1991: Gradual implementation of guidelines concerning drugs and disease states; frequent evaluation; and adequate education of prescribers, dispensers, and consumers should lead to a health care system in which formal policy isn't needed.

\section{THE CHALLENGE TO MCOS}

All of these systems present problems when application is attempted in MCOs. 
As organization size, patient diversity, and geographic area increase, the opportunity for missed data, inaccurate interpretation, and incomplete communication also increase.

HealthPartners Health Plans (HPHP), a 140,000-member plan in southern Arizona which fills 1.2 million prescriptions annually, uses a network model of organization. HPHP had tried DUR/DUE, with unsatisfactory results. A team of clinical pharmacists and medical directors reviewed their process and results to determine why prescribing practices were not changing sufficiently. The team members determined that the manner in which results were communicated to prescribers must be the problem, and they began looking for alternatives and enhancements.

\section{THE ADVENT OF ACADEMIC DETAILING}

In the early 1980s, Jerry Avorn, M.D. and some of his colleagues coined the term "academic detailing." In a series of articles, they explored the idea that clinical pharmacists could approach prescribers much like medical sales representatives did. However, instead of promoting specific products, they would present information on appropriate use of medication in selected disease states. The theory was that these pharmacists, if trained in sales methods similar to those used by drug manufacturers, could effectively influence prescribing habits (see Table 2). This method offered certain advantages over established monitoring techniques.

Most notable, academic detailing focuses on precise information, presents the message in an agreeable way, and contributes to an improved prescriber-pharmacist relationship. The rationale behind this theory is sound. Pharmaceutical manufacturers' promotional activities reach more practitioners than do educators' activities. Although our goals are different, similar methods can be used to increase and improve educational contact. The quality of information provided by medical sales representatives recently has come under media scrutiny. And academic detailing offers the opportunity to present factual material that is broader in scope

Table 2. Medical Sales Detailing vs. Academic Detailing

\begin{tabular}{lll}
\hline ASPECT OF PROCESS & \multicolumn{1}{c}{$\begin{array}{c}\text { MANUFACTURER'S } \\
\text { INTENT }\end{array}$} & \multicolumn{1}{c}{$\begin{array}{c}\text { ACADEMIC } \\
\text { DETAILER'S INTENT }\end{array}$} \\
\hline Purpose & Sell specific drug, generate profit & $\begin{array}{l}\text { Teach rational prescribing, decrease } \\
\text { suboptimal prescribing }\end{array}$ \\
\hline Scope of activity & Manufacturer's product only & Entire category of drugs \\
\hline Cost & $>\$ 3$ billion annually & Varies \\
\hline Tools & $\begin{array}{l}\text { Prepared by marketing department } \\
\text { with entire market in mind }\end{array}$ & $\begin{array}{l}\text { Prepared by pharmacy department } \\
\text { with or without input from medical } \\
\text { staff and direcied at own prescribers }\end{array}$ \\
\hline Process & Face-to-face encounter in & $\begin{array}{l}\text { Face-to-face encounter in } \\
\text { prescriber's office }\end{array}$ \\
\hline Methods & Influential tools of communication & \begin{tabular}{l} 
Influential tools of communication \\
\hline Outcome
\end{tabular} \\
\hline Increased sales of specific agent & $\begin{array}{l}\text { Increased general knowledge and } \\
\text { greater likelihood of rational } \\
\text { prescribing }\end{array}$ \\
\hline
\end{tabular}

than that presented by salespeople. It also offers pharmacists an opportunity to correct misperceptions created by sales visits.

Eventually, studies indicated that pharmacist visits to prescribers were successful, but message impact declined over time. This was not an unexpected finding, since medical sales representatives' messages also lose their effect over time; however, it did emphasize the importance of making frequent visits.

\section{PROJECT PLANNING}

As in most other managed care organizations, HPHP had practiced drug utilization extensively, using data collected over months or years. However, large quantities of information created processing problems and sometimes the data was eight to 12 months in arrears. Lag time reduced information integrity and sending results through the mail had little impact. The HPHP team decided that a collage of tools was needed to increase impact and, consequently, influence decision making.

Clinical pharmacists at HPHP believed that the academic detailing model had some interesting implications for managed health care and could be a more appropriate way to influence prescribing prospectively. The lesson they learned from prescriber comments after completion of criteria-based DUR was that information concerning individual prescribing patterns could be extremely powerful. Their goal was to decrease prescriber variance, defined as wide variance in use of medication to treat the same illness or condition.

In their search for background information, HPHP's pharmacists found a model described by Brent James, M.D., of Salt Lake City, to be extremely helpful. His work explained a technique employed in an inpatient setting which provided comprehensive prescriber information and compared individuals to their peers in the same practice specialty. $\mathrm{He}$ demonstrated that a decrease in variance could increase quality.

\section{PREPARATION: KEY TO SUCCESS- FUL ACADEMIC DETAILING}

The idea of academic detailing was attractive and exciting to the clinical pharmacy staff at HPHP. However, they realized that adequate preparation, including review of detailing methods and training in key techniques, was needed before they could start.

The first task was presenting their message in a logical, rational order that Continued on page 637 
Continued from page 633

would appeal to the prescriber's information needs as opposed to the facility's fiscal process needs. Physical presentation must be orderly and attractive, as well as simple and concise. Working with the pharmacy benefits managers, this team developed an individual prescriber profile which they initially called a prescriber report card. The team selected a format that fit on one sheet and could be folded to resemble a greeting card. These report cards are now mailed very shortly after quarterly data is compiled. They include the following information for the prescriber:

- Information about the therapeutic category most frequently prescribed by the clinician, average cost of each agent, and a brief review of the clinician's peer group pattern.

- A profile of the prescriber's clientele, describing age and gender.

- Usage rates for generic drugs and controlled substances, plus average number of prescriptions per patient, average cost of prescriptions per patient, and average cost of medication overall

- Graphic displays to compare agents within a pharmacologic class and highlight appropriate drug use in the class.

- Specific focus on a class of drugs, enhanced with the prescriber's own prescribing profile for the target class, including average dose of target agents, average cost, and comparison to peers.

After careful consideration of other principles of successful influence, the team changed the name of the prescriber report card to Prescriber Information Report (PIR). The PIR had several strengths. First was its simplicity and format. Second, the PIR's size and design made it a convenient desk tool to help prescribers quickly reference differences among agents in a class.

After finishing the PIR, the team looked for ways to enhance presentation. A program was created for display on a laptop computer, including a visual display of

\section{Table 3. Communication Techniques for Academic Detailers}
$\Delta$ Use face-to-face approach
A Frame message in therapeutic perspective
$\Delta$ Consider the prescriber's information needs and communication style
$\Delta$ Make message simple, direct, and concise
$\Delta$ Select no more than three important points that must be communicated
$\Delta$ Repeat important information but don't repeat
A Lead naturally lo a conclusion
A Use colorful, professional visual aids
A Listen
A Collaborate to combine your unique knowledge bases and determine a course of action
$\Delta$ know your audience
- Assess outcome and use self-critique to improve too often

all information present on the PIR. It allows fluid, quick review of all prescribing information in the prescriber's office

Planners believed that graphic display would appeal to physicians and add an instrument to their arsenal of tools. Armed with comprehensive information, the academic detailer is prepared to answer questions and provide additional information. The structure of the program facilitates discussion, assists the detailer with prescriber questions, and complements the printed PIR.

Finally, the clinical team suggested that physicians would be more receptive to the program if continuing medical education (CME) units were available for its completion. They consulted the director of teaching programs at HPHP's major hospital. Although the program's utility was initially questioned, CME evaluators for Arizona's state medical society were eventually impressed. The program was approved for CME credits; over two years, approximately $100 \mathrm{CME}$ credits have been issued. Physicians receive one unit of credit for presentations that are 45 minutes to one hour long. Attached CME credit has been an incentive for physicians and has added an aspect of credibility to presentations.

\section{PROGRAM SUCCESS SPEAKS FOR ITSELF}

This program has been used since the fourth quarter of 1994. Since then, 150 academic detailing sessions have been scheduled. Most have been individual appointments, but academic detailers also have met with small groups of physicians, often in the same specialty. HPHP pharmacists would like to increase the number and frequency of academic detailing sessions. However, they face many of the same problems that medical sales representative do without budgets specifically designated to support their activities. Travel, office space, and scheduling are considerable obstacles. This process requires a large investment of time when preparation and personnel costs are considered. However, feedback from clinicians indicates that the program is worth the cost.

The PIR has been particularly well received. Unsolicited comments from prescribers have been very positive; they speak to the utility of this tool and its presentation. Prescribers consider the rapid turnaround time for information and blind comparisons with peers important incentives to the report's use and application. Their ability to use the PIR and make deductions based on objective data has made it a cooperative process.

Of course, the program is not without some problems. Unfortunately, the time required to run day-to-day operations of a large managed care organization often takes precedence over other activities. Scheduling and travel often take a back seat to other activities. While oneon-one detailing in a physician's office improves the effect of message delivery, it is time consuming. Academic detailing is not a drop-in activity; it requires careful planning. Successful influence by pharmacists also depends on presentation intensity fortified with excellent communication skills. Table 3 describes some of the detailing techniques pharmacists must master to build confidence and guarantee superior communication.

Uninterrupted flow of information is necessary to assure continuity in this elaborate system. This has been most difficult. 
Four hundred PIRs are generated and mailed each quarter, and this process can be burdensome. If it is not given priority, the advantage of quick information distribution is lost.

As with any clinical program, ongoing evaluation and justification has been necessary. HPHP has developed new evaluation tools that better assess aggregate data and demonstrate changes in prescribing. Specific influence is difficult to measure, but longitudinal impact over time is being monitored. Additionally, pharmacist academic detailers have started keeping post-interview notes about topics discussed and plans for the next visit. Information gathered with these tools will help HPHP target information that is more useful to the prescriber, and thus more influential. Conclusions will be drawn to justify continuation of the program.

\section{FUTURE PROSPECTS TO IMPROVE INFLUENCE}

Physician education and feedback is more important than ever. A flood of new drugs to treat increasingly complex disease states will require better information about drug use and interactions. Directto-consumer advertisements will place physicians and pharmacists on the defensive when prescribing and answering patient's questions. The demise of formulary systems will increase the potential for prescriber variability. With some managed care organizations moving toward prescriber assumption of risk for pharmacy expense, academic detailing may become an important educational device for physicians.

Under any circumstances, educational programs for prescribers are mandatory if they are to understand the role they play in risk management. Use of academic detailing is an innovative way to influence prescribers toward rational, cost-effective prescribing in a manner that emphasizes cooperation through education, rather than restrictive policies.

\section{ACADEMIC DETAILING AND HMG COA AGENTS}

In 1995, HealthPartners Health Plans included four HMG CoA agents on their formulary. After careful review, members of the medical and pharmacy staffs jointly decided that they would designate fluvastatin (Lescol) as the preferred agent and simvastatin (Zocor) as copreferred for those patients who did not respond to fluvastatin. At the project's start, almost no fluvastatin was being dispensed. HPHP used the following techniques to create their collage of interventions:

A The content of the quarterly PIR was directed at this class of drugs, emphasizing the advantages of fluvastatin and simvastatin.

A Newsletter articles were prepared stressing advantages of each agent.

A Wall charts promoting preferred therapy were distributed to physician offices.

$\Delta$ Academic detailing was directed at this category.
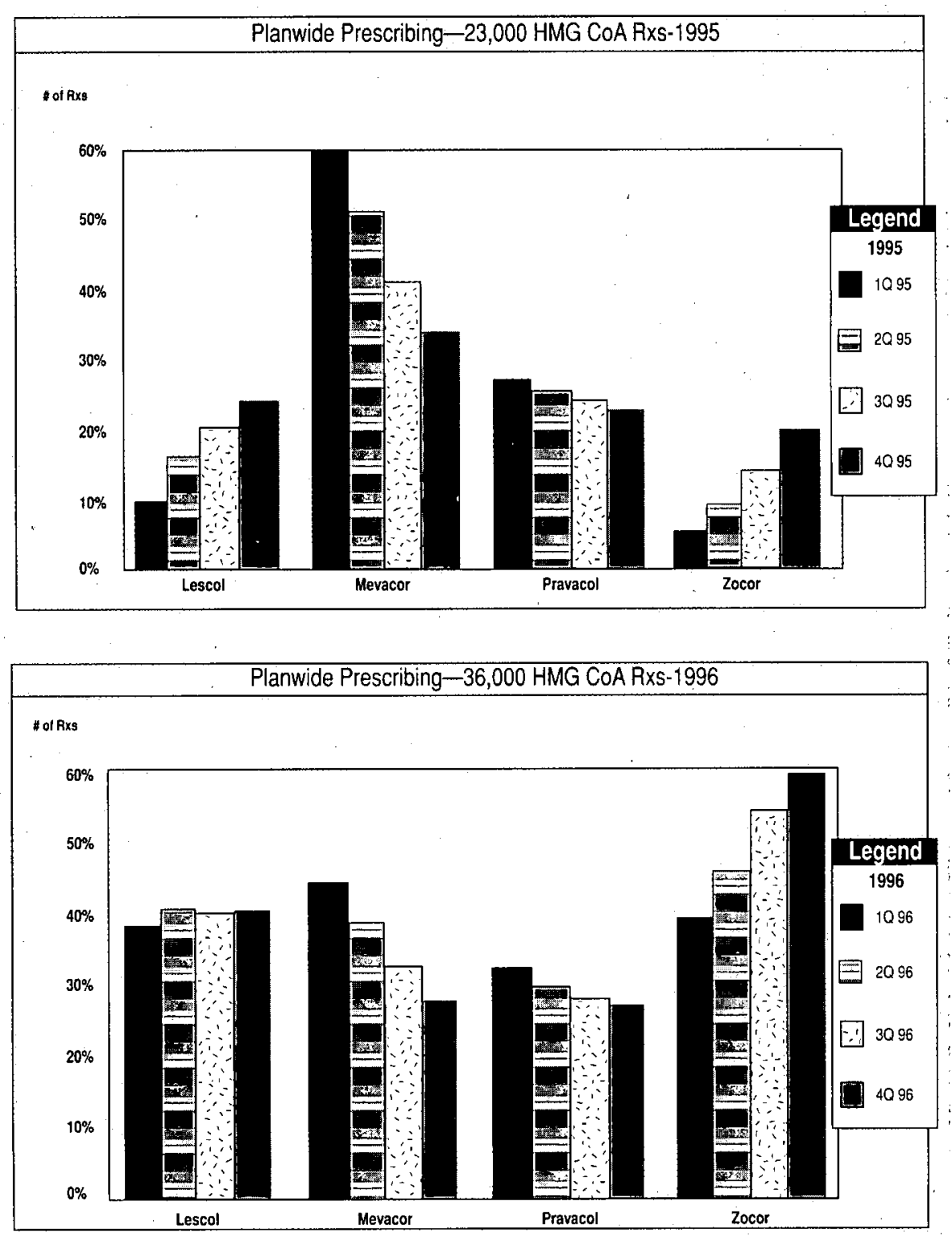